\title{
Brasil e Alemanha na semifinal da Copa do Mundo: representações sobre a derrota no discurso de Zero Hora
}

\section{STEFFEN, Lauren}

\author{
Mestranda em Comunicação Midiática (linha: Mídia e Identidades Contemporâneas) pelo Programa \\ de Pós-Graduação em Comunicação da UFSM. (lauren.ssteffen@gmail.com)
}

\section{LISBOA FILHO, Flavi Ferreira}

\begin{abstract}
Doutor em Ciências da Comunicação (linha: Mídias e Processos Audiovisuais) pela Unisinos. Professor Adjunto do Departamento de Ciências da Comunicação e do Programa de Pós-Graduação em Comunicação da UFSM. (flavilisboa@gmail.com)
\end{abstract}

\section{Resumo}

O presente artigo pretende discutir as representações sobre a derrota da Seleção Brasi-leira para a Alemanha na semifinal da Copa do Mundo de 2014 em matéria publicada pelo jornal Zero Hora. Para tanto, recupera-se o contexto histórico e a perspectiva dos Estudos Culturais para a problematização das relações entre sociedade, cultura e meios de comunicação, com destaque para o conceito de representação, central para a compreensão dos processos de produção de sentidos postos em circulação no meio social. O percurso teórico está ancorado nas estruturas de sentimento (emergentes, dominantes e residuais). A análise de discurso é utilizada como técnica para identifica-ção dos sentidos, mapeando as formações discursivas presentes no discurso jornalístico. Este trabalho reforça os pressupostos de que os significados são produzidos discursiva-mente através da linguagem a partir do repertório cultural de um contexto determinado.

Palavras-chave: Jornalismo; Estudos Culturais; representação; estruturas de sentimento; Seleção Brasileira.

\begin{abstract}
This article discusses the representations of the defeat of the Brazilian national team to Germany in the semifinal of the World Cup 2014 in a report published by the newspaper Zero Hora. It recovers the historical context and the perspective of the Cultural Studies to understand the relationship between society, culture and the media, especially the concept of representation, central to understand the production of senses put into circulation in the social environment. The theoretical course is anchored in the structures of feeling (emerging, dominant and residual). The discourse analysis is used as a technique to identify the senses, mapping the discursive formations in the journalistic discourse. This work reinforces the assumption that meanings are discursively produced through language from the cultural repertoire of a given context.
\end{abstract}

Keywords: Journalism; Cultural Studies; representation; structures of feeling; Brazilian national team.

\section{Resumen}

Este artículo analiza las representaciones de la derrota de la selección de Brasil a Alemania en la semifinal de la Copa del Mundo en 2014 en un informe publicado por el diario Zero Hora. Recupera el contexto histórico y la perspectiva de los Estudios Culturales para entender la relación entre la sociedad, la cultura y los medios de comunicación, especialmente el concepto de representación, fundamental para entender la producción de sentidos puestos en circulación en el entorno social. El curso teórico está anclado en las estructuras de sentimiento (emergente, dominante y residual). El análisis del discurso se utiliza como una técnica para identificar los sentidos, mapeando las formaciones discursivas en el discurso periodístico. Este trabajo refuerza la suposi-ción de que los significados se producen discursivamente a través del lenguaje del re-pertorio cultural de un contexto dado.

Palabras clave: Periodismo; Estudios Culturales; representación; estructuras de sentimiento; Selección brasileña. 


\section{Introdução}

Este artigo realiza, em sua primeira subseção, uma incursão teórica sobre o campo da análise de discurso (AD), descrevendo suas especificidades e estratégias. Na subseção seguinte, o conceito de formações discursivas é desenvolvido, abrangendo sua centralidade dentro da área do discurso para entender como se dá a construção das regi-ões de sentido dominantes ao longo da análise. A partir deste estudo, são identificados os sentidos construídos a respeito da derrota da Seleção Brasileira na semifinal da Copa do Mundo de 2014 no discurso jornalístico de Zero Hora, em reportagem publicada no dia og de julho de 2014, um dia após a derrota da Seleção Brasileira na semifinal da Copa do Mundo de futebol por 7 a 1. O jornalista Diogo Olivier, enviado especial do jornal a Belo Horizonte (MG), local da partida, relata a atuação dos jogadores brasilei-ros. $\mathrm{O}$ título da matéria é "Brasil é goleado pela Alemanha e vê morrer sonho do título em casa".

Através da utilização da metodologia da análise de discurso, foram mapeadas as formações discursivas presentes no discurso jornalístico a fim de elucidar os conceitos apresentados na fundamentação teórica. Por fim, esta pesquisa traz o tensionamento entre a cultura, a sociedade e os meios de comunicação a partir dos Estudos Culturais, destacando o papel fundamental das representações sociais para a construção dos signi-ficados e das identidades. As estruturas de sentimento são trazidas a fim de evidenciar as características dominantes, residuais e emergentes, que permitem articular a experi-ência do indivíduo com as estruturas sociais.

\section{Análise de discurso}

A análise de discurso (AD) procura compreender como a linguagem cria senti-dos, enquanto trabalho simbólico constitutivo do homem e de sua história; entende a linguagem como mediação necessária entre o homem e a realidade social. Segundo Or-landi (2009), essa mediação, que é o discurso, torna possível tanto a continuidade quan-to o deslocamento do homem e da realidade em que ele vive. O trabalho simbólico do discurso está na base da produção da existência humana.

De acordo com Orlandi (2009), esse método de pesquisa assume a linguagem como um instrumento simbólico repleto de possíveis equívocos, uma vez que não há neutralidade nem mesmo no uso aparentemente banal dos signos. O jornalismo busca empregar uma linguagem supostamente objetiva, o que, na perspectiva da análise de discurso, se mostra uma utopia, pois não há garantia de que haja convergência de inter-pretação entre os interlocutores. O jornalista pode apenas direcionar o sentido do seu texto, mas não pode controlar a sua compreensão.

O jornalismo narra a sociedade para a própria sociedade, por meio de um texto construído a partir de elementos exteriores ou anteriores, como a história, o senso co-mum e a cultura. A análise de discurso busca identificar onde esses elementos estão inseridos nessa linguagem, e também procura mapear as vozes presentes no discurso jornalístico, que se diz polifônico, mas nem sempre possui enunciadores plurais que apresentam conhecimentos a partir de diversos pontos de vista: “[...] apenas a pluralida-de de perspectivas de enunciação pode configurar o jornalismo como um campo plural e representativo da diversidade social” (BENETTI, 2008, p. 120).

A análise de discurso não considera a linguagem transparente, ou seja, não crê na imanência do sentido. Ela não procura identificar qual o sentido do texto, mas se pergunta como determinado texto significa. Ela produz um conhecimento a partir do próprio texto, pois o vê como ten- 
do uma materialidade simbólica, uma espessura se-mântica: ela o concebe em sua discursividade (ORLANDI, 2009).

Para a $\mathrm{AD}$, toda linguagem é dialógica, podendo ser pensada em dois planos: a relação entre discursos e a relação entre sujeitos. A primeira relação diz respeito à inter-discursividade, termo associado ao fato de que um texto é sempre atravessado por ou-tros textos. A segunda diz respeito à intersubjetividade, isto é, ao fato de que o discurso não existe por si mesmo, ele só existe em um espaço entre sujeitos (BENETTI, 2007). O discurso depende dos sujeitos para existir, o que significa que seu sentido é opaco e ple-no de possibilidades de interpretação.

Na produção do discurso, um dos elementos fundamentais é a memória enquanto interdiscurso, representando aquilo que é dito em outro momento, em outro lugar, por outras vozes, e que determina o sentido do discurso atual de formas muitas vezes in-consciente. Assim, o sentido não existe de forma individual, mas é determinado por posições ideológicas, o que faz com que as palavras mudem de sentido de acordo com a posição do sujeito que as emprega.

Partindo da ideia de que a materialidade específica da ideologia é o discurso e a materialidade específica do discurso é a língua, a AD trabalha a relação língua-discurso-ideologia (Orlandi, 2009). Como diz Pêcheux (1997), não há discurso sem sujeito e não há sujeito sem ideologia: o indivíduo é interpelado pela ideologia e é assim que a língua faz sentido. Consequentemente, o discurso é o lugar em que se pode observar essa rela-ção entre língua e ideologia, compreendendo-se como a língua produz sentido por/para os sujeitos.

\section{Formações discursivas}

Para Orlandi (2009), a noção de formação discursiva é básica na análise de dis-curso, pois permite compreender o processo de produção de sentidos, a sua relação com a ideologia e também possibilita o estabelecimento de regularidades no funcionamento do discurso. A formação discursiva se define como aquilo que em uma formação ideo-lógica dada determina o que pode e deve ser dito.

A partir desta definição, é possível compreender que as palavras não têm sentido nelas mesmas, pois derivam seus sentidos das formações discursivas em que se inscre-vem. Orlandi (2009) explica que as formações discursivas podem ser vistas como regio-nalizações do interdiscurso, configurações específicas dos discursos em suas relações, já que todo discurso se delineia na relação com dizeres presentes e dizeres que se instalam na memória.

Dessa forma, os sentidos não estão predeterminados por propriedades da língua, mas dependem de relações constituídas pelas formações discursivas. Orlandi (2009) ressalta que as formações discursivas não são configuradas como blocos homogêneos, funcionando automaticamente. Elas são marcadas pela heterogeneidade e pela contradi-ção, com fronteiras fluidas e instáveis.

Segundo Benetti e Jacks (2001), uma formação discursiva é definida como aqui-lo que pode e deve ser dito, em oposição ao que não pode e não deve ser dito. O indiví-duo cindido em vários sujeitos só pode falar porque se desloca e se descentra. Assim, o sujeito sempre fala de algum lugar e este lugar pode ser diferente daquele que ocupou há um minuto. 
Para definir uma formação discursiva, o analista precisa trabalhar com regras de formação do discurso, ou seja, as condições a que estão submetidos os elementos de uma repartição (FOUCAULT, 1995). Segundo o autor, uma formação discursiva é defi-nida por um certo número de enunciados que apresentam semelhante sistema de disper-são e a que corresponde uma regularidade entre os objetos, os tipos de enunciação, os conceitos e as escolhas temáticas. Tais regras definem como um mesmo sentido é cons-truído ao longo de enunciados distintos.

Benetti (2007) salienta que a análise inicia sempre no próprio texto, no movi-mento de identificação das formações discursivas (FDs). "Uma FD é uma região de sen-tidos, circunscrita por um limite interpretativo que exclui o que invalidaria aquele senti-do" (BENETTI, 2007, p. 112). A interpretação deve se limitar à reunião, em torno de uma $\mathrm{FD}$, de diversos pequenos significados que consolidam um sentido nuclear. Benetti (2007) ressalta que existem tantas formações discursivas quanto sentidos nucleares em um texto.

Benetti (2007, p. 111) explica que "o texto é a parte visível ou material de um processo altamente complexo que inicia em outro lugar: na sociedade, na cultura, na ideologia, no imaginário". A intenção do método é justamente tornar visível a reunião, raramente aparente, das forças que compõem o texto. Assim, existem, no texto, duas camadas: uma mais visível (camada discursiva) e outra que só se torna evidente quando aplicado o método (camada ideológica).

Segundo Orlandi (2009), todo o funcionamento da linguagem se assenta na ten-são entre processos parafrásticos e processos polissêmicos. Os processos parafrásticos são aqueles pelos quais em todo dizer há sempre algo que se mantém, isto é, o dizível, a memória. A paráfrase representa, assim, o retorno aos mesmos espaços do dizer. Rela-ciona-se com a ideia de estabilização. Ao passo que, na polissemia, o que temos é des-locamento, ruptura de processos de significação, relacionando-se intrinsecamente com o equívoco. Essas formas trabalham continuamente o dizer, de tal modo que todo discurso se faz nessa tensão entre o mesmo e o diferente. Dessa forma, a incompletude é a condi-ção da linguagem: nem os sentidos nem os sujeitos estão prontos e acabados. Eles se constituem na relação tensa entre paráfrase e polissemia. Assim, "os sentidos e os sujei-tos sempre podem ser outros, dependendo de como se inscrevem na história" (OR-LANDI, 2009, p. 37).

Todo discurso é norteado pelo que se imagina sobre o outro. É necessário que os dois sujeitos envolvidos no processo possam compreender a posição de sujeito do outro, além da sua própria. Aqui, é importante destacar o conceito de formação imaginária. Segundo Benetti (2008), o sujeito que fala tem dois horizontes imaginários ao longo dos quais se desloca na enunciação dirigida a um interlocutor, refletindo sobre si e sobre o outro. Em contrapartida, o próprio interlocutor lida com a imagem que faz de si e do outro. O jornalista que enuncia tem uma imagem sobre si, seu papel e sua identidade. Esse jornalista também tem uma imagem sobre seu leitor. "Para que o discurso jornalís-tico aconteça, os interlocutores devem reconhecer as permissões e restrições dos sistemas de formação do jornalismo, sendo capazes de reconhecer os elementos que definem o gênero" (BENETTI, 2008, p. 5).

Algumas regiões de sentido predominam na reportagem de Zero Hora, confor-mando formações discursivas que estabelecem regularidades no funcionamento do dis-curso. Através da utilização da análise de discurso enquanto técnica para mapear os sen-tidos, foram encontradas quatro formações discursivas ao longo do discurso jornalístico: a) compaixão, que caracteriza o 
comportamento dos jogadores alemães em relação aos jogadores brasileiros; b) vexame, que assinala o significado da derrota do Brasil na se-mifinal da Copa do Mundo; c) constrangimento, que corresponde à reação da torcida brasileira diante da atuação dos jogadores da Seleção e d) prepotência, que identifica a atitude do técnico da Seleção Brasileira em relação à escalação dos jogadores.

As formações discursivas são exemplificadas por sequências discursivas, trechos do discurso jornalístico que elucidam a região de sentido definida. As partes destacadas em negrito são os sentidos dominantes que justificam as formações discursivas encontradas na análise. As formações discursivas serão relacionadas com as perspectivas residual, dominante e emergente a fim de aprofundar o entendimento das representações construídas.

A formação discursiva de compaixão foi constantemente empregada para carac-terizar o comportamento dos jogadores alemães em relação à Seleção Brasileira. Nas sequências discursivas a seguir, é possível perceber que o discurso do jornalista ressaltou a piedade dos jogadores alemães, que inclusive não fizeram mais gols na partida por "pura compaixão" ao time brasileiro. Essas sequências acentuam a superioridade da Seleção Alemã em campo, que poderia ter aumentado ainda mais o placar, mas resolveu diminuir o ritmo de jogo no segundo tempo.

(1) Por pura compaixão da Alemanha, que teve piedade no segundo tempo, não foi oito ou no-ve (gols).

(2) Por compaixão, a Alemanha tirou o pé no segundo tempo.

(3) O jogo escorreu pelo ralo da vergonha, com a Alemanha tendo piedade do Brasil.

A segunda formação discursiva encontrada foi a de vexame, que assinala o signi-ficado da derrota do Brasil para a Alemanha em uma semifinal de Copa do Mundo por 7 a 1. Essa formação discursiva permeia todas as outras, pois é a região de sentido mais forte identificada ao longo do discurso jornalístico de Zero Hora. Reiteradamente, o discurso do jornalista destaca a vergonha do resultado da partida, caracterizando-a como o "maior fiasco brasileiro em toda a sua história de Copas". O tom trágico utilizado pelo discurso jornalístico deixa transparecer que a derrota foi o fim de um sonho para milhões de brasileiros de ver a Seleção conquistar o sexto título no Brasil. A escolha das palavras (tragédia, fiasco, vexame, vergonha, fracasso) salienta a opinião do discurso jornalístico sobre a partida, ressaltando o quanto a atuação da Seleção humilhou e constrangeu os milhares de torcedores que estavam no estádio mineiro.

(4) Vexame mundial: Brasil é goleado pela Alemanha e vê morrer sonho do título em casa

(5) Uma Seleção Brasileira mal escalada pelo seu técnico deixa a Copa do Mundo assinando o maior vexame de sua história futebolística, levando 7 a 1 em uma semifinal disputada dentro de casa.

(6) Foi constrangedor, do início ao fim. Um suplício.

(7) Do outro lado, um Brasil desprotegido no meio-campo, aberto, varzeano, uma baderna tá-tica, errando lances bisonhos e assustado com a superioridade do oponente.

(8) O primeiro tempo foi humilhante.

(9) Bernard, escalado para ser a surpresa corajosa de Felipão, tornou-se um fracasso.

(10) Diante deste cenário, em pouco menos de meia hora, o maior fiasco brasileiro em toda a sua história de Copas estava consumado.

(11) A partir daí, foi treino. 
(12) O jogo escorreu pelo ralo da vergonha, com a Alemanha tendo piedade do Brasil.

(13) Em vez de superar a ausência de Neymar com superação e valentia, a tragédia esportiva. O futebol brasileiro nunca mais esquecerá o seu pior fiasco em todas as Copas.

A terceira formação discursiva identificada foi a de constrangimento, que sinali-za a reação da torcida brasileira em relação à atuação da Seleção em campo. Nesta FD, é ressaltada a perplexidade dos jogadores diante da série de gols sofrida pelo Brasil, que resultou em sofrimento e xingamentos, mostrando o quanto a torcida estava atônita com o resultado da partida. Esse sentido reforça o quanto foi vergonhosa a atuação do time brasileiro, considerado um dos melhores do mundo e sobre o qual se depositavam muitas expectativas para a conquista do sexto título em Copas do Mundo.

(14) Ninguém entendia nada no Mineirão.

(15) Os torcedores brasileiros se olhavam, atônitos. Outros choravam. Depois, xingaram.

A quarta e última formação discursiva mapeada foi a de prepotência, que identi-fica a atitude do técnico da Seleção Brasileira em relação à escalação dos jogadores. É possível perceber que grande parte da culpa pela derrota da Seleção Brasileira na partida é depositada na escalação feita pelo técnico Luís Felipe Scolari. O discurso jornalístico reforça a prepotência de Felipão ao apostar em um jogador (Bernard) que não tinha condições de preencher a posição ocupada por Neymar, que se lesionou pouco antes da semifinal. Mesmo assim, o técnico manteve sua escolha, em uma atitude denotada pela arrogância e falta de humildade, segundo o discurso de Zero Hora.

(16) Com cinco gols marcados ainda no primeiro tempo, alemães fizeram 7 a 1 no time de Feli-pão.

(17) Uma Seleção Brasileira mal escalada pelo seu técnico deixa a Copa do Mundo.

(18) Luiz Felipe Scolari poderia ter sido humilde e se defendido, reconhecendo o melhor fute-bol do adversário.

(19) Mas Felipão resolveu abandonar suas origens e se abriu, com toques de soberba.

\section{Estruturas de sentimento}

Os Estudos Culturais são considerados uma perspectiva teórico-metodológica que analisa as relações entre sociedade, práticas culturais e meios de comunicação de massa. O campo de estudos iniciou na Inglaterra, de forma organizada, a partir da cria-ção do Centre for Contemporary Cultural Studies (CCCS) em 1964. O Centro surge ligado ao Departamento de Língua Inglesa da Universidade de Birmingham, constituin-do-se em um centro de pesquisa de pós-graduação.

As origens dos Estudos Culturais remontam a três textos publicados no final da década de 50: Richard Hoggart com The Uses of Literacy (1957), Raymond Williams com Culture and Society (1958) e E. P. Thompson com The Making of the English working-class (1963). Segundo Escosteguy (2010, p. 137), tal campo de estudo surge tanto sob o ponto de vista político quanto sob o ponto de vista teórico, já que pode ser identificado como "a política cultural dos vários movimentos sociais da época de seu surgimento".

A constituição dos Estudos Culturais reflete a insatisfação com os limites de al-gumas disciplinas, propondo a interdisciplinaridade como forma de estudo das articula-ções culturais 
presentes na sociedade. Para entender as aplicações teórico-metodológicas do campo, torna-se fundamental analisar o conceito de cultura. De acordo com Raymond Williams (1991), um dos fundadores dos Estudos Culturais, a cultura compreende sentidos diversos,

[...] desde um estado mental desenvolvido - como em "pessoa de cultura", "pessoa culta", passando pelos processos desse desenvolvimento - como em "interesses culturais", "atividades culturais", até os meios desses processos - como em cultura considerada como as artes e o trabalho intelectual do ho-mem. Em nossa época é o sentido geral mais comum, embora todos eles se-jam usuais. Ele coexiste com o uso antropológico e o amplo uso sociológico para indicar "modo de vida global" de determinado povo ou de algum outro grupo social. (WILLIAMS, 1991, p.11)

O foco de atenção dos Estudos Culturais recai sobre produtos culturais populares e massivos, que antes eram desprezados. Tal ampliação do conceito de cultura considera a validade de todas as formas de expressão, superando a tradicional divisão entre alta e baixa cultura e tornando possível o desenvolvimento convergente desse conceito em uma abordagem crítica e interdisciplinar, ou seja,

[...] de textos e representações para as práticas vividas -, considera-se em fo-co toda a produção de sentido. O ponto de partida é a atenção sobre as estruturas sociais (de poder) e o contexto histórico enquanto fatores essenciais para a compreensão da ação dos meios massivos, assim como o deslocamento do sentido da cultura da sua tradição elitista para as práticas cotidianas. (ESCOSTEGUY, 2010, p.143)

A própria visão sobre os meios de comunicação de massa sofre um deslocamento profundo, já que não são vistos como meros reprodutores da estabilidade social, uma vez que também se adaptam às pressões da sociedade, integrando-as ao próprio sistema cultural. Assim, o massivo deixa de ser o lugar da manipulação para transformar-se em lugar de negociação.

Schulman (2010) destaca o rompimento dos Estudos Culturais com as concep-ções passivas e indiferenciadas de público, partindo para a análise dos modos como as mensagens são codificadas pelos diferentes receptores, conforme o contexto social e político. O campo passa a defender que, no âmbito popular, não existe somente submis-são, mas também há espaço para resistência e intervenção social.

O conceito de representação torna-se essencial para a compreensão da construção dos significados no interior dos sistemas sociais, uma vez que é, por meio da linguagem, que os objetos do mundo são construídos. De acordo com Hall (2006), a cultura é um conjunto de sistemas classificatórios a que a língua recorre para dar signi-ficado aos objetos, diferenciando-os dos demais. Assim, o sentido é socialmente cons-truído a partir da linguagem e da representação, tendo como base um sistema comum de classificação chamado cultura.

Para descrever a relação entre as experiências dos indivíduos e a estruturação social, como elementos constitutivos da cultura, Williams cunha, em 1954, o termo "es-truturas de sentimento", que pode ser compreendido como uma resposta às mudanças determinadas e ocorridas na organização social. Enquanto proposição metodológica, "uma 'estrutura de sentimento' é uma hipótese cultural, derivada na prática de tentativas de compreender esses elementos e suas ligações, numa 
geração ou período, e que deve sempre retornar, interativamente, a essa evidência" (WILLIAMS, 1979, p. 135).

Segundo o referido autor, as estruturas de sentimento se referem às formações sociais já existentes na sociedade, relacionadas às vivências de um determinado tempo e lugar, ou seja, "a cultura de um período: o resultado vital e específico de todos os ele-mentos da organização geral" (WILLIAMS, 2003, p.57, tradução nossa), ligadas às formações dominantes ou residuais e relacionadas com as formações emergentes, as novas práticas sociais vividas pelos indivíduos.

As características percebidas através das perspectivas dominante, residual e emergente servem para pensar os produtos midiáticos como frutos de uma prática social localizada no tempo e na história, uma vez que são atravessados por essas três instâncias.

Conforme aponta Moraes (2011), a perspectiva dominante corresponde ao mo-delo estabelecido e reconhecido pelos indivíduos. É o espaço das práticas legitimadas e consolidadas como referência em determinada cultura. Tendo como exemplo o objeto empírico de análise, podemos citar como uma perspectiva dominante o fato de que a Seleção Brasileira era considerada a favorita na Copa do Mundo, o que gerou muitas expectativas quanto à possibilidade de conquistar o sexto título jogando em casa. Havia ainda uma confiança enorme na competência do técnico brasileiro, Luiz Felipe Scolari, que já havia vencido a Copa do Mundo de 2002 a frente da equipe.

A perspectiva residual compreende a busca pelos resquícios dos modelos estabelecidos no passado, podendo alternar-se, ou mesmo, opor-se ao dominante. Como afirma Williams (1979, p.125), "o residual, por definição, foi efetivamente formado no passado, mas ainda está vivo no processo cultural, não só como elemento do passado, mas como elemento efetivo do presente". Tendo como base a reportagem de Zero Hora, podemos destacar como residual o passado de vitórias da Seleção Brasileira em Copas do Mundo, constituindo-se como a única seleção a participar de todas as edições e a ganhar cinco títulos no campeonato mundial, o que reforça o imaginário de superiorida-de no esporte e marca a própria construção da identidade brasileira enquanto "país do futebol".

Há ainda a perspectiva emergente, que contesta as práticas residuais e dominan-tes em função do surgimento do novo, onde novos valores e ideias passam a contrapor as práticas dominantes existentes, representando "áreas da experiência, aspiração e rea-lização humanas que a cultura dominante negligencia, subvaloriza, opõe, reprime ou nem mesmo pode reconhecer" (WILLIAMS, 1979, p. 127).

Tendo como base o objeto empírico de análise, é possível identificar como emergente a compaixão dos jogadores alemães, que se sensibilizaram com o fracasso de uma das melhores seleções de futebol do mundo. Além disso, pode-se definir como emergente o sentido de vexame e constrangimento expresso pelo discurso jornalístico, mostrando que a torcida brasileira foi humilhada diante do desempenho vergonhoso da Seleção, que colocou um fim ao sonho de milhões de brasileiros. A caracterização do técnico da Seleção Brasileira como prepotente pelo discurso jornalístico também é emergente, visto que Luiz Felipe Scolari trazia novas esperanças para a equipe e sempre foi retratado como uma pessoa humilde e como um profissional competente, capaz de dar aos brasileiros o sexto título no mundial. 


\section{Considerações finais}

Este artigo teve como objetivo discutir as representações sobre a derrota da Se-leção Brasileira para a Alemanha na semifinal da Copa do Mundo em reportagem publi-cada pelo jornal Zero Hora, no dia 09 de julho de 2014. Para tanto, o percurso teórico abordou os estudos culturais enquanto campo de análise das articulações entre cultura, sociedade e meios de comunicação de massa.

Em seguida, como forma de relacionar as experiências do indivíduo e as estru-turas sociais, buscou-se caracterizar as estruturas de sentimento, termo cunhado por Raymond Williams, um dos fundadores dos Estudos Culturais. A partir dessa metodo-logia, apontou-se, partindo do objeto empírico de análise, caracterizar as instâncias do-minantes, residuais e emergentes presentes no discurso jornalístico.

A análise de discurso mostrou-se fundamental para compreender a produção de sentidos enquanto prática social e cultural, resultante de um determinado contexto. O conceito de formações discursivas, básica para a análise de discurso, permitiu identificar a construção das significações, a sua relação com a ideologia e o estabelecimento de regularidades no funcionamento do discurso.

Todas essas regiões de sentido dominantes demonstram que o jornalista ocupou uma determinada posição de sujeito ao longo do discurso e que as palavras utilizadas não significam por si mesmas, mas fazem sentido dentro do contexto de suas condições de produção. Nota-se, dessa forma, que o conceito de formação discursiva é central para compreender o funcionamento do discurso, seus deslocamentos e regularidades. As es-truturas de sentimento possibilitaram o aprofundamento da análise a partir da compre-ensão de que, em toda manifestação social, perpassam instâncias dominantes, emergen-tes e residuais, que caracterizam a cultura de um período, as estruturas que atravessam gerações e permeiam as práticas sociais do presente.

\section{Referências bibliográficas}

BENETTI, Marcia; JACKS, Nilda. O discurso jornalístico. In: Encontro Anual da As-sociação Nacional dos Programas de Pós-Graduação em Comunicação, 10, 2001. Anais GT de Jornalismo. Brasília: Compós, 2001.

BENETTI, Marcia. Análise do discurso em jornalismo: estudo de vozes e sentidos. In: BENETTI, Marcia; LAGO, Cláudia (Orgs.). Metodologia de pesquisa em Jornalismo. Petrópolis: Vozes, 2007.

BENETTI, Marcia. O jornalismo como gênero discursivo. Galáxia, n. 15. São Paulo: PUCSP, 2008.

ESCOSTEGUY, Ana Carolina. Estudos Culturais: uma introdução. In: SILVA, Tomaz Tadeu da. (org.). O que é, afinal, Estudos Culturais?. Belo Horizonte: Autêntica, 2010, p. 135-166.

FOUCAULT, Michel. A arqueologia do saber. 4 ed. Rio de Janeiro: Forense Universitá-ria, 1995. 
HALL, Stuart. A identidade cultural na pós-modernidade. Rio de Janeiro: DP\&A, 2006.

ORLANDI, Eni. Análise de discurso: princípios e procedimentos. 8. ed. Campinas: Pontes, 2009.

PÊCHEUX, Michel. Semântica e discurso. 3. ed. Campinas: Unicamp, 1997.

SCHULMAN, Norma. O Centre for Contemporary Cultural Studies da Universidade de Birmingham: uma história intelectual. In: SILVA, Tomaz Tadeu da. (org.). O que é, afinal, Estudos Culturais?. Belo Horizonte: Autêntica, 2010, p. 167-224.

WILLIAMS, Raymond. Marxismo e literatura. Rio de Janeiro: Zahar, 1979.

\section{Apêndice}

Vexame mundial

Brasil é goleado pela Alemanha e vê morrer sonho do título em casa

Com cinco gols marcados ainda no primeiro tempo, alemães fizeram 7 a 1 no time de Felipão

por Diogo Olivier, enviado especial a Belo Horizonte (MG)

$09 / 07 / 2014$

Um, dois, três, quatro, cinco, seis, sete. Por pura compaixão da Alemanha, que teve piedade no segundo tempo, não foi oito ou nove. Dez, talvez. Uma Seleção Brasi-leira faceira, mal escalada pelo seu técnico, deixa a Copa do Mundo assinando o mai-or vexame de sua história futebolística, levando 7 a 1 em uma semifinal disputada den-tro de casa.

Foi constrangedor, do início ao fim. Um suplício. O que se viu foi um time or-ganizado, compactado, capaz de fluir um contra-ataque com meia dúzia de passes rápi-dos e se fechar em bloco logo em seguida em questão de segundos. Esta era a Alemanha.

Do outro lado, um Brasil desprotegido no meio-campo, aberto, varzeano, uma baderna tática, errando lances bisonhos e assustado com a superioridade do oponente. Sem Neymar, Luiz Felipe Scolari poderia ter sido humilde e se defendido, reconhecendo o melhor futebol do adversário.

Até treinou com Paulinho em seu lugar, formando um tripé de volantes para marcar o setor mais forte dos alemães, que há anos todos sabem ser o meio-campo. Mas Felipão resolveu abandonar suas origens e se abriu, com toques de soberba. Escolheu o pequenino Bernard, escancarando suas entranhas. A Alemanha se serviu.

O primeiro tempo foi humilhante. 
Bernard, escalado para ser a surpresa corajosa de Felipão, tornou-se um fracasso. Mal tocou na bola. Sumiu diante do gigante Hoewedes, o lateral-esquerdo que o mar-cou. Hulk, do outro lado, seguiu igual aos outros jogos. Força, vontade, espaço para avançar mas, quando tinha de tocar na bola, errava.

Oscar jogou ao lado de Luiz Gustavo, incompreensivelmente. Assim, com a linha de três atrás de Fred em total naufrágio, nem deu para culpar o centroavante, de novo inoperante.

Diante deste cenário, em pouco menos de meia hora, o maior fiasco brasileiro em toda a sua história de Copas estava consumado. Depois do primeiro gol, de Müller, logo aos 10 minutos, a Seleção se desintegrou. Ninguém entendia nada no Mineirão. Aos 22, Klose marcou o seu $16^{\circ}$ gol em Mundial, superando Ronaldo. Até isso.

Aos 24, Kroos aumentou. Não perca a conta. 3 a o. Aos 25, o mesmo Kroos, se aproveitando de uma lambança de Luiz Gustavo e Fernandinho à frente da área, formou o quatrilho. Aos 29, Khedira, um dos volantes que o Brasil não se importou em marcar, se desprendeu lá de trás e fez o quinto gol.

A partir daí, foi treino.

Os alemães cantavam "Rio de Janeiro, ô, ô, ô", trocando o jota por xis. Os torce-dores brasileiros se olhavam, atônitos. Outros choravam. Depois, xingaram Fred, quando este atrasou uma bola para o goleiro. Em seguida, repetiram a dose com Oscar. E até Bernard. E quase todos os jogadores brasileiros.

Por compaixão, a Alemanha tirou o pé no segundo tempo. As entradas de Pauli-nho e Ramires nos lugares de Fernandinho e Hulk, é claro, melhoraram o Brasil na volta do intervalo. Dois volantes, que ajudaram a marcar o forte meio-campo alemão. Paulinho quase assinalou o de honra aos 8 minutos, obrigando Neuer a se aquecer um pouco e fazer ótima defesa.

O jogo escorreu pelo ralo da vergonha, com a Alemanha tendo piedade do Brasil, até o apito final do mexicano Marco Rodríguez. Ainda houve tempo para Schürrle fazer o sexto e o sétimo. E o que se viu no Mineirão foi a história ao contrário. O gol de honra de Oscar foi quase uma galhofa.

Em vez de superar a ausência de Neymar com superação e valentia, a tragédia esportiva. $\mathrm{O}$ futebol brasileiro nunca mais esquecerá o seu pior fiasco em todos as Copas. 